\title{
Empirical Analysis of Network Reciprocity's Impacts on Universities' Cross-Region Technology Transfer Performance
}

\author{
Yi Tang \\ The School of Public Affairs, University of Science and Technology of China, Hefei, China \\ Email: tang2006122@126.com
}

How to cite this paper: Tang, Y. (2017) Empirical Analysis of Network Reciprocity's Impacts on Universities' Cross-Region Technology Transfer Performance. Open Journal of Social Sciences, 5, 384-395. https://doi.org/10.4236/jss.2017.55026

Received: May 4, 2017

Accepted: May 24, 2017

Published: May 27, 2017

Copyright $\odot 2017$ by author and Scientific Research Publishing Inc. This work is licensed under the Creative Commons Attribution International License (CC BY 4.0).

http://creativecommons.org/licenses/by/4.0/ (c) (i) Open Access

\begin{abstract}
Based on the analysis of the network theories, assumptions are raised about how the reciprocity influences the transfer, and theoretical models are established accordingly. Variables reflecting network reciprocity and technology transfer performance are chosen and measured based on the study of assumptions. Regression analysis of panel data is adopted to study the relation between the variables, and the result is used to verify the assumptions. Finally, corresponding advices on policy making and future study are raised according to the research results. Through empirical analysis, it is illustrated that the performance of cross-region technology transfer is improved with the increase of the region's reciprocity relationship in the transfer network. The reciprocity relationship can significantly promote the import, export and transfer level of universities' technologies. The region's participation level of reciprocity cliques can accelerate the export of technology but has no significant impact on technology transfer.
\end{abstract}

\section{Keywords}

Universities, Cross-Region Technology Transfer, Network Reciprocity,

Transfer Performance

\section{Introduction}

University is an important part of a country's innovation system, and the transfer of its technological achievements is a crucial drive to the region's innovation and economic development. Due to restrictions such as geographic distance and regional policies, the transfer tends to take place locally, which leads to two consequences: on one hand, the difference of innovation levels among different regions caused by the imbalance of education resources is increased, with innova- 
tion ability of regions equipped with a large number of universities continuously becoming stronger while that of those regions with inadequate resources becomes worse; on the other hand, the industries in a certain region are limited, which prevents the universities' technology outcomes from being fully utilized and transferred. Cross-region technology transfer can break these restrictions and form positive interaction of innovation resources including technology resources, capital and human resources between universities and industries, and also between different regions, which can effectively bridge the gap of resource difference and coordinate the development.

When studying the influencing factors of universities' cross-region technology transfer, current researchers mainly adopt two-dimensional analysis and focus on the influences caused by the technology itself, the subjects involved in the transfer and the transfer environment, with only a few of the researchers studying the impacts of network relations such as cross-region transfer ties or clique relationship. However, many studies and cases have demonstrated the importance of social network in the transfer process [1] [2]. This report raises assumptions about the relationship between network reciprocity and the transfer based on relevant theories, and establishes theoretical models, and through regression analysis verifies the models, and then based on the empirical analysis results, investigates network reciprocity's impacts on the technology transfer.

\section{Literature Review}

The concept of "reciprocity" originated from biology, the theory of which was raised to solve altruism problem faced by Classic Darwinism. Later on, the concept of reciprocity preference was widely applied in many fields such as sociology, economics and management, especially behavioral economics, with Robin introduced the concept into the whole research structure to establish the foundation of this discipline [3]. Robin defined "reciprocity" as following behaviors: 1) sacrifice one's own benefit to help another individual from whom the main subject has received help before; 2) sacrifice one's own benefit to punish another individual who is unfriendly to the main subject; 3) the two behavior modes above can influence others' behaviors more significantly when one's own benefit loss is minor or when the improvement of others' benefits is greater [4]. This theory changed the classic economics' assumption of "rational economical men" by holding the opinion that not only an individual's economical behaviors can help achieve benefits, but the interaction with other individuals can also maximize one's own benefits. Reciprocity preference involves two processes including reciprocity motivation and reciprocity behavior. The motivation refers to the willing of paying someone back or carrying out revenge at a certain cost of benefit, and the behaviors resulted from the motivation are called reciprocity behaviors.

In the study of the impacts on social relationship caused by reciprocity, it is believed that based on reciprocity principle, individuals tend to balance the gain and cost, which means to pay back for others' help and revenge others' hostility. 
After a reciprocity relationship is established between two individuals, the relation can last longer and easier to maintain compared with non-reciprocity relationship, and interactions carried out based on reciprocity principles can strengthen the relationship as well [5]. With the development of this theory, reciprocity principles are now applied not only between individuals, but are also expanded to study the relationship between different groups. On this new level, the study mainly focuses on the network reciprocity among groups. Network reciprocity refers to the equivalent relationship in which subjects from different network rely on each other [6]. Earlier measurement of network reciprocity level mainly depended on the proportion of reciprocity relations [7]. Researchers think that reciprocally related subjects have more stable and equivalent relationships. The reciprocity relationship is also called "strong-strong tie". Feng zhao Liu believes that with the deepening of the technology transfer process, the relationship between different regions would turn from "weak-weak" tie to "strong-strong" tie [8]. Recently, network reciprocity is widely applied when studying the performance of technology transfer and enterprises. Herderson and Cockburn found out that network reciprocity can strength the confidence between subjects and therefore improve the spread efficiency of tacit knowledge [9]. Jingwei Liu et al. believe that management strategies and team culture based on reciprocity principles can help form a mutual vision, and the reciprocity preference between team members can accelerate the spread of tacit knowledge and the realization of mutual vision, which leads to the advancement of a team's innovation ability [10].

However, former research mainly focuses on enterprise level study. With the development of the university technology research, more and more universities' technology transfer into enterprise and other institution. If the network reciprocity could influence the universities' cross regional technology transfer has seldom been researched. In the network, reciprocity relationship not only includes reciprocity ties, but how different reciprocity relationships influence technology transfer needs further research.

\section{Research Assumptions}

\subsection{The Relationship between Network Reciprocity and the Performance of Cross-Region Technology Absorption}

The process of universities' technology transfer is accompanied with knowledge exchange and regional technology innovation. To transfer technology into another region, subjects need to break the geographic limitation and pay larger cost, which leads to higher requirements for the relationship between the involved subjects. In the study of technology absorption performance, many variables have been considered including the location of the network and the strength of relations. As to network reciprocity, it is always considered as a crucial factor that influences the transfer and knowledge exchange. Grannovetter views reciprocity as an important criterion to evaluate the strength of relations in directed networks, and holds the opinion that subjects with "strong-strong" 
tie have a relationship with better confidence and stability. In the process of knowledge exchange, Zhaowen Lin thinks that reciprocity relationship can optimize traditional mode of knowledge transfer, and the receiver can achieve better effect of transfer due to the exporter's reciprocity preference [11]. Reciprocity relationship also implies the existence of mutual confidence and learning, and this kind of interactive mechanism can encourage technology exchange level between the subjects, and finally realizes technology innovation. Technology is the carrier of knowledge; therefore, the transfer of technology means the spread of knowledge. A region's technology innovation is the ultimate purpose of crossregion technology transfer.

In terms of technology absorption, the stable relationship with mutual confidence across regions based on reciprocity network can create reciprocity preference among technology producers which reduces the confidence risk. Besides, reciprocity network can shape frequent tunnels between regions which eliminate unnecessary communication and study and increase the absorption efficiency. A hypothesis is raised as follows:

H1: Network reciprocity can positively influence the absorption performance of cross-region technology transfer. To the receivers, building more reciprocity relationships in the transfer network can benefit their absorption of the technology.

\subsection{The Relationship between Network Reciprocity and the Performance of Cross-Region Technology Export}

There exists a severe information imbalance between the market and the universities, which are the subjects of the export side in the transfer process, due to the absence of market mechanism's guidance in universities' technology export. In the past, the transfer was dominated by universities and governments instead of the inventors of the technologies. As a result, the application scope and tacit knowledge of the technologies was not fully understood, which increased the difficulty of transfer. Information imbalance can easily lead to failure in the process of commercialization if the technologies are transferred one-way or occasionally. On the other hand, confident relationship can be established between the subjects, which refer to the universities, and media of the transfer, which include industries, universities and governments of other regions, basing on the reciprocity networks, and therefore reduces the risk and increases the proportion of industrialization of the exported technologies. Besides, reciprocal transfer mode can create more communication opportunities between the subjects and decrease the cost and difficulty, which leads to knowledge spread with higher efficiency. Additionally, the alliance between universities and industries across regions can guide the universities to develop technologies more suitable for industries' development therefore enables continuous technology export. As a result, technology innovation and industry development can keep inspiring each other and form the "Matthew Effect" in technology transfer which can realize mutual development of various regions. A hypothesis is raised as follows: 
H2: Network reciprocity can positively influence the export performance of cross-region technology transfer. Subjects with more reciprocity relationships can reach higher level of technology export.

\subsection{The Relationship between Network Reciprocity and the Performance of Cross-Region Technology Transfer}

Combining the deduction of hypothesis $\mathrm{H} 1$ and $\mathrm{H} 2$, and analysis of universities' technology transfer network, the report holds the view that reciprocity network has significantly positive effects on the overall performance of cross-region technology transfer. A hypothesis is raised as follows:

H3: Network reciprocity can positively influence the performance of crossregion technology transfer. With more reciprocity relationship in the transfer network, a region has better import and export ability and therefore higher transfer standard.

Based on the hypothesis, this paper select several indexes including reciprocity ties, clique and so on to measure variables and collect the related panel data. Then through regression analysis to verify if the dependent variables have a significant effect on dependent variable. Finally, based on the relationship between dependent variables an independent variable is to confirm the hypothesis.

\section{Index Selection and Measurement}

\subsection{Indexes of Network Reciprocity}

Indexes of network reciprocity consists of two types, respectively reciprocity relations and sub-groups. Researchers usually assess the strength of relations in directed networks by viewing whether the relations are reciprocal, and the reciprocal ones are considered as strong relations and function crucially in promoting technology transfer [12]. Network sub-group based on reciprocity is called a clique, which requires strict one-on-one reciprocity relations between its members. Cliques are viewed as sub-groups with frequent interaction, and can significantly enhance the transfer of complicated knowledge.

Transfer networks are established in this report basing on universities' cross-province patent transfer data. The patent data are collected from Incopat patent database which contains information of all types of patent application, authorization and quotation in China, from Incopat, this paper select whole invention patent from university from 2007-2016, then classify into different provinces. Based on the patent date, cross regional technology transfer network was established. 31 Chinese provinces are chosen as the nodes of the network. The number of reciprocity relations and cliques between the nodes is calculated to work as indexes in the network reciprocity measurement using network analysis software UCINET. Since the transfer network is a network with directions and multi-values, the number needs to be calculated by binaryzation and symmetrizing of the transfer network of the past years using UCINET. In the binaryzation, relationships with relations are defined as 1 , and the ones without relations are defined as 0 . In the symmetrizing, the smaller number of the two sym- 
metrical numbers in the matrix is adopted as the replacement of the two numbers. In the final symmetrized matrix, number 1 is viewed as reciprocity relationship while number 0 is viewed as non-reciprocity one. The number of reciprocity relations owned by each network nodes, which is the reciprocity technology transfer relations owned by each province, can be obtained by adding the numbers together. The participation number of cliques is obtained by adding the cliques' participation number of each node (i.e. of each province) together using clique analysis function of UCINET.

\subsection{Indexes of Technology Transfer Performance}

In earlier researches, Chapple et al. adopted the number of patent permission as the index to measure technology transfer performance while Thursby used the transaction price of patents as the index to evaluate the transfer efficiency [13] [14].

Considering the difficult achievement, relatively poor quality and limited valid time of patent data in China, Chinese researchers mainly chose the number of signed technology transfer contracts or incomes as indexes to measure the transfer performance in the past. However, there exists time-delay for these indexes therefore they can't fully reflect the real transfer situations of that time [15]. In recent years, the numbers of patent transfer and permission keep increasing, and this change enables the researchers to use these numbers to measure the output of technology transfer [16]. The number of universities' patented technology export (which is the sum of transfer and permission) is adopted as the index to measure technology export performance while the number of patented technology imported by the regions as the index to measure the absorption performance. The sum of patent export and import number is considered as the number of patent transfer. The number of patent transfer was also collected from Incopat database.

\subsection{Selection of Controlled Variables}

According to the Ba Linsen function model and other research results, the two sides of the technology transfer are considered as major influences in the transfer. In terms of technology supply, the innovation level of a region or an organization can directly affect the transfer export level. Universities' research input, researchers' quality, transfer mode and management can also impose influences. Therefore, at the side of technology supply, universities' R\&D achievements application in the regions, the cost of scientific research and the amount of patent permission are chosen as the controlled variables.

In terms of technology demand, the technology import level is influenced by the scale of the receivers' demand and their absorption ability to a large extent. Bonai Fan used DEA to assess the universities' technology transfer efficiency in the 31 provinces and applied regression analysis to the regional GDP and the transfer efficiency. The result showed a significant positive correlation between the GDP and efficiency [17]. Cohen defines absorption ability as the receivers' 
earlier development accumulation and technological knowledge foundation [18]. Subjects with better absorption ability can accept new technology and knowledge more rapidly. Therefore, the regional GDP is selected as the controlled variable at the demanding side.

To conclude, this report conducts analysis from two sides, respectively the supply and demand of technology, and selects three controlled variables including universities' R\&D achievements application and scientific research cost of the year, the amount of patent permission of the year and the regional GDP. The data of these variables are collected from Chinese Statistic Yearbook and Chinese Technological Statistic Yearbook.

\section{Model Establishment}

According to the deduction and hypotheses mentioned above, a theoretical model of the relationship between network reciprocity and universities' crossregion technology transfer performance can be established as follows, in which the network reciprocity is the independent variable and consists of two dimensions including the number of reciprocity ties and the participation of reciprocal cliques, which can be obtained by measuring the existing transfer network. The transfer performance is the dependent variable and contains three dimensions including the performance of export, absorption and transfer, which can be obtained by measuring the number of patented technology transfer. The universities' R\&D achievements application and scientific research cost of the year, the amount of patent permission of the year and the regional GDP are controlled variables. The following Figure 1 is the specific model.

\section{Empirical Analysis}

\subsection{Descriptive Statistics Analysis}

In order to study the relationship between network reciprocity and universities' cross regional technology transfer. This paper does correlation analysis and regression analysis by STATA. The data of 31 provinces from 2010 to 2016 are chosen to establish the panel data sample for all the variables. The number of

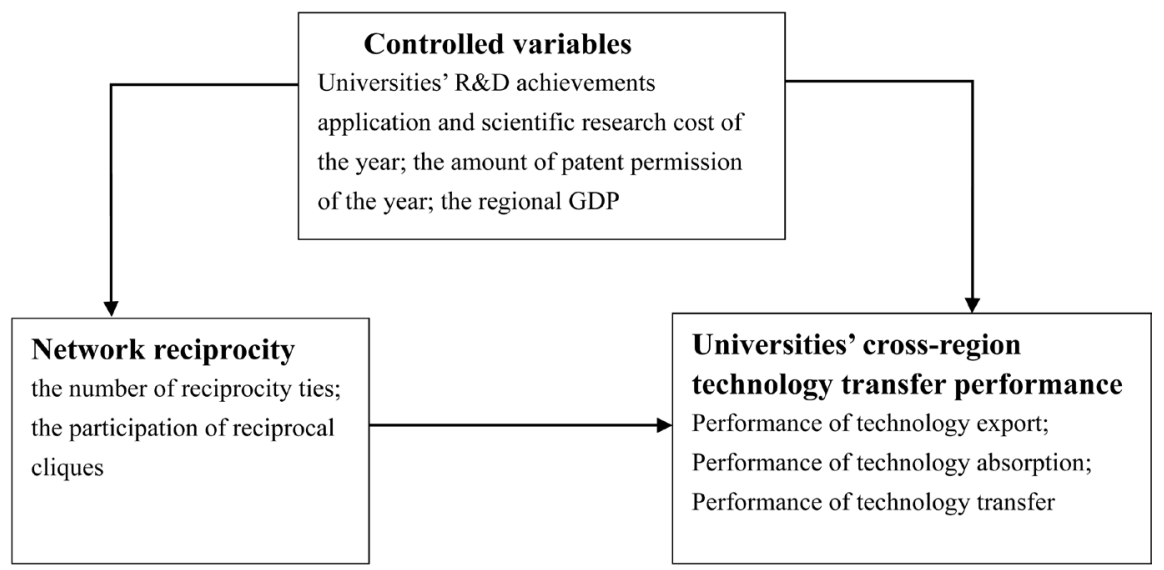

Figure 1. Theoretical model. 
samples for each variable is 217 (the number of those variables with missing data is smaller than 217). The descriptive analysis is shown in Table 1. It is illustrated that the average value of the reciprocal relations and reciprocity cliques' participation numbers are both small, which implies that the overall reciprocity level of the transfer network is still low. As to the three indexes of the dependent variable, there exists a big difference between the maximum and minimum value and a large standard deviation, which indicates a big gap between the transfer performances of various regions and an imbalance of regions' technological innovation and absorption level. Therefore, universities' cross-region technology transfer is necessary as an effective approach to narrow the gap.

\subsection{Correlation Analysis}

To avoid the error caused by collineation of variables, their correlation is examined before the regression analysis. As is shown in Table 2, the correlation coefficient for reciprocal relation number and export performance is $0.7578^{\star}$, which means they are significantly positively correlated; the correlation coefficient for reciprocal relation number and transfer performance is $0.8446^{\star}$, indicating a significant positive correlation; the coefficient for reciprocal relation number and absorption performance is $0.6407^{\star}$, indicating a significant positive correlation. The coefficient for reciprocity cliques' participation number and export performance is $0.7134^{\star}$, indicating a significant positive correlation; the coefficient for reciprocity cliques' participation number and transfer performance is $0.8182^{\star}$, indicating a significant positive correlation; the coefficient for reciprocity cliques' participation number and absorption performance is $0.6390^{*}$, indicating a significant positive correlation. The results of correlation analysis demonstrate a significant correlation between network reciprocity and technology transfer performance, which lays the foundation of regression analysis.

Table 1. The result of descriptive statistics analysis.

\begin{tabular}{|c|c|c|c|c|c|c|}
\hline & & Number & Average & Maximum & Minimum & $\begin{array}{l}\text { Standard } \\
\text { deviation }\end{array}$ \\
\hline \multirow{2}{*}{$\begin{array}{l}\text { Independent } \\
\text { variable }\end{array}$} & $\begin{array}{l}\text { The number of } \\
\text { reciprocity ties }\end{array}$ & 217 & 1.4 & 15.0 & 0.0 & 2.6 \\
\hline & $\begin{array}{c}\text { The number of reciprocal } \\
\text { cliques' participation }\end{array}$ & 217 & 0.6 & 12.0 & 0.0 & 1.6 \\
\hline \multirow{3}{*}{$\begin{array}{l}\text { Dependent } \\
\text { variable }\end{array}$} & $\begin{array}{c}\text { The number of } \\
\text { technology absorption }\end{array}$ & 217 & 33.8 & 565.0 & 0.0 & 67.9 \\
\hline & $\begin{array}{l}\text { The number of } \\
\text { technology export }\end{array}$ & 217 & 33.6 & 314.0 & 0.0 & 55.3 \\
\hline & $\begin{array}{l}\text { The number of } \\
\text { technology transfer }\end{array}$ & 217 & 65.1 & 675.0 & 0.0 & 97.0 \\
\hline \multirow{3}{*}{$\begin{array}{l}\text { Controlled } \\
\text { variable }\end{array}$} & $\begin{array}{c}\text { The regional GDP (hun- } \\
\text { dreds of millions) }\end{array}$ & 217 & 20037.7 & 79512.1 & 1150.1 & 21336.5 \\
\hline & $\begin{array}{c}\text { Universities' R \& D cost } \\
\text { (thousand) }\end{array}$ & 217 & 418235.3 & 2460164.0 & 8.0 & 522617.0 \\
\hline & $\begin{array}{c}\text { The amount of patent } \\
\text { permission }\end{array}$ & 217 & 1175.8 & 2537.4 & 0.0 & 1779.0 \\
\hline
\end{tabular}


Table 2. The result of correlation analysis.

\begin{tabular}{|c|c|c|c|c|c|}
\hline & \multicolumn{3}{|c|}{ Technology Technology Technology } & \multicolumn{2}{|c|}{ Reciprocity Reciprocal cliques' } \\
\hline & export & transfer & absorption & ties & participation \\
\hline Technology export & 1.0000 & & & & \\
\hline Technology transfer & $0.7657^{*}$ & 1.0000 & & & \\
\hline Technology absorption & $0.3367^{*}$ & $0.8655^{*}$ & 1.0000 & & \\
\hline Reciprocity ties & $0.7578^{*}$ & $0.8446^{\star *}$ & $0.6407^{*}$ & 1.0000 & \\
\hline $\begin{array}{c}\text { Reciprocal cliques' } \\
\text { participation }\end{array}$ & $0.7134^{*}$ & $0.8182^{*}$ & $0.6390^{*}$ & $0.9477^{*}$ & 1.0000 \\
\hline
\end{tabular}

Notes: ${ }^{\star} \mathrm{P}<0.05,{ }^{*} \mathrm{P}<0.01$.

\subsection{Regression Analysis}

The regression analysis of panel data is carried out using STATA and the Fixed Effect model is selected. The results are as follows:

(1) Model 1: relationship between network reciprocity and regions' technology absorption performance

The result of regression analysis for these variables is demonstrated in Table

3. The P value of the Fixed Effect model is 0.0000 , indicating that the whole model is statistically significant therefore is meaningful in the sense of statistical regression. The value of $\mathrm{R} 2$ is 0.4868 , showing a moderate fitting degree, so the result can reflect the relation between the independent and dependent variables. The $\mathrm{P}$ value of the reciprocal relation number and the absorption performance is 0.023 , which is less than 0.05 , showing a significant positive correlation with the coefficient value of 9.4482 . The $\mathrm{P}$ value of the reciprocity cliques' participation number and the absorption performance is 0.197 , which fails in the significance test meaning there exists no significant correlation. Conclusions can be drawn that a region's absorption performance can become better with a larger number of reciprocal relations, while the reciprocity cliques' participation number has no significant positive influence on the absorption performance.

(2) Model 2: relationship between network reciprocity and regions' technology export performance

The result is demonstrated in Table 4 . The whole model is statistically significant. The value of $R^{2}$ is 0.6766 , showing a better fitting degree than that of model 1 , and can reflect the relation between the independent and dependent variables effectively. The $\mathrm{P}$ value of the reciprocal relation number and the export performance is 0.003 , which is less than 0.05 , showing a significant positive correlation with the coefficient value of 9.402671 . The $\mathrm{P}$ value of the reciprocity cliques' participation number and the export performance is 0.032 with the coefficient value being at 4.378463 , indicating a significant positive correlation between the two variables. Conclusions can be drawn that a region's export performance can be improved with a larger number of reciprocal relations and reciprocity cliques' participation.

(3) Model 3: relationship between network reciprocity and regions' technology transfer performance 
Table 3. Regression Analysis result of network reciprocity and regions' technology absorption performance.

\begin{tabular}{|c|c|c|c|c|}
\hline Model 1 & $\mathrm{R}^{2}$ & 0.4868 & Prob $>$ F & 0.0000 \\
\hline Technology absorption & Coef. & Std. Err. & & \\
\hline Reciprocity ties & 9.4482 & 4.104881 & & \\
\hline Reciprocal cliques' participation & 7.464676 & 5.767346 & & \\
\hline
\end{tabular}

Table 4. Regression Analysis result of network reciprocity and regions' technology export performance.

\begin{tabular}{|c|c|c|c|c|}
\hline Model 2 & $\mathrm{R}^{2}$ & 0.6766 & Prob $>$ F & 0.0000 \\
\hline Technology export & Coef. & Std. Err. & & \\
\hline Reciprocity ties & 9.402671 & 3.168735 & & \\
\hline Reciprocal cliques' participation & 4.378463 & 4.447629 & & \\
\hline
\end{tabular}

The result is demonstrated in Table 5. The $\mathrm{P}$ value of the reciprocal relation number and the transfer performance is 0.000 and the coefficient value is 18.89839 , which shows a significant positive correlation. The $\mathrm{P}$ value of the reciprocity cliques' participation number and the transfer performance is 0.643 , which fails in the significance test meaning there is no significant correlation between the two variables. Results of the analysis show a large coefficient value between the reciprocal relation number and the transfer performance, illustrating that the former variable has strong impacts on the latter one, while no significant positive correlation is found between the reciprocity cliques' participation number and the transfer performance.

The verification result of the hypotheses achieved from the correlation and regression analysis is demonstrated in Table 6. For the two indexes of network reciprocity, it is verified that the number of relations can significantly influence the cross-region technology transfer performance, while the correlation between reciprocity cliques' participation number and the absorption or transfer performance is not shown. According to the analysis of theories and network features mentioned in the former sections, the participation number is believed to be able to affect the transfer performance. However, this effect is not shown in the regression analysis. A possible explanation is that the number of existing reciprocity cliques in the current transfer network is not big enough to create a significant influence.

\section{Conclusions}

With the modification and transformation of economic structures, the important role of innovation in promoting economic development is more and more clear. Since universities are a major resource of innovation, how to enhance the transfer performance of their technology outcomes has become a focus. By analyzing the impacts on transfer performance resulted from the features of transfer network structure and network reciprocity, this study believes that an effective 
Table 5. Regression Analysis result of network reciprocity and regions' technology transfer performance.

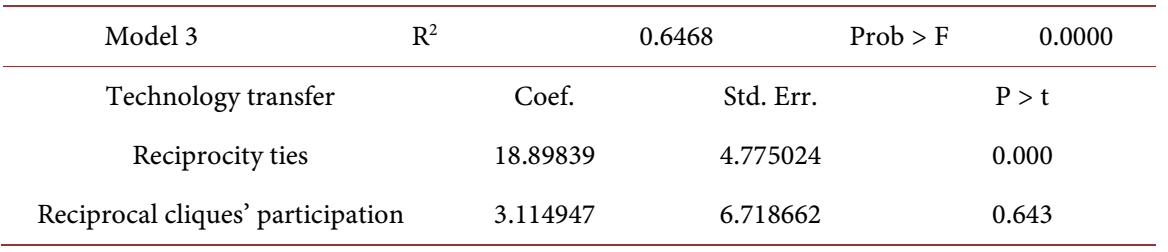

Table 6. Verification results of the hypotheses achieved.

\begin{tabular}{|c|c|c|}
\hline Hypothesis & Contents & Result \\
\hline $\begin{array}{l}\text { H1: Network reciprocity can } \\
\text { positively influence the }\end{array}$ & $\begin{array}{l}\text { the number of ties can significantly influence } \\
\text { absorption performance }\end{array}$ & Verified \\
\hline $\begin{array}{l}\text { absorption performance of } \\
\text { cross-region technology transfer. }\end{array}$ & $\begin{array}{l}\text { reciprocity cliques' participation number can } \\
\text { significantly influence the absorption performance }\end{array}$ & Unverified \\
\hline $\begin{array}{l}\mathrm{H} 2 \text { : Network reciprocity can } \\
\text { positively influence the export }\end{array}$ & $\begin{array}{l}\text { the number of ties can significantly influence } \\
\text { export performance }\end{array}$ & Verified \\
\hline $\begin{array}{l}\text { performance of cross-region } \\
\text { technology transfer. }\end{array}$ & $\begin{array}{l}\text { reciprocity cliques' participation number can } \\
\text { significantly influence the export performance }\end{array}$ & Verified \\
\hline $\begin{array}{l}\text { H3: Network reciprocity can } \\
\text { positively influence the }\end{array}$ & $\begin{array}{l}\text { the number of ties can significantly influence } \\
\text { transfer performance }\end{array}$ & Verified \\
\hline $\begin{array}{l}\text { performance of cross-region } \\
\text { technology transfer. }\end{array}$ & $\begin{array}{l}\text { reciprocity cliques' participation number can } \\
\text { significantly influence the transfer performance }\end{array}$ & Unverified \\
\hline
\end{tabular}

way to promote the transfer level in order to realize mutual innovation of different regions is to create more reciprocal relations and establish transfer alliances among the innovative subjects. However, this paper only verifies that network reciprocity has positive influence on cross regional technology transfer, but how reciprocity relations influence technology transfer and why reciprocity clique cannot influence technology transfer haven't been studied. In the future study, it is highly suggested that more research should be carried out on how to fully use the advantages of different subjects such as governments, universities, enterprises and transfer medium in the transfer process, to shape more reciprocal network relations and to achieve more efficient usage and exchange of innovation resources in the network.

\section{References}

[1] Reagans, R. and McEvily, B. (2003) Network Structure and Knowledge Transfer: The Effects of Cohesion and Range. Administrative Science Quarterly, 48, 240-267. https://doi.org/10.2307/3556658

[2] Lin, J.L., Fang, S.C., Fang, S.R. and Tsai, F.S. (2009) Network Embeddedness and Technology Transfer Performance in R\&D Consortia in Taiwan. Technovation, 29, 763-774. https://doi.org/10.1016/j.technovation.2009.05.001

[3] Rabin, M. (1998) Psychology and Economics. Journal of Economic Literature, 36, 11-46.

[4] Rabin, M. (1993) Incorporating Fairness into Game Theory and Economics. The American Economic Review, 83, 1281-1302.

[5] Gouldner, A.W. (1960) The Norm of Reciprocity: A Preliminary Statement. Ameri- 
can Sociological Review, 25, 161-178. https://doi.org/10.2307/2092623

[6] Xie, H.M., Wang, X.B., Wu, S. and Yu, W. (2008) Research on Cluster Network and the Innovation of Ijvs. Science Research Management, 29, 23-29.

[7] Hanneman, R.A. and Riddle, M. (2005) Introduction to Social Network Methods. University of California, California.

[8] Liu, F.C. and Ma, R.K. (2013) Study on the Network Structure and Spatial Distribution of Inter-Regional Technology Transfer: Analysis Based on Inter-Provincial Technical Market Transaction of China in 2006-2010. Studies in Science of Science, 31, 529-536.

[9] Henderson, R. and Cockburn, I. (1994) Measuring Competence? Exploring Firm Effects in Pharmaceutical Research. Strategic Management Journal, 15, 63-84. https://doi.org/10.1002/smj.4250150906

[10] Liu, J.W., Zhang, T.J. and Lin, Z.W. (2009) The Empirical Research of Technique Innovation Capability of Technique Exploration Team Based on Reciprocal Enterprise Environment. Studies in Science of Science, 27, 1093-1100.

[11] Lin, Z.W., Zhang T. J. and Pu, Y.J. (2008) Research on The Impact of It Capability and Information Sharing Against the R\&D Collaboration Between Enterprises. Science Research Management, 29, 28-33.

[12] Bresman, H., Birkinshaw, J. and Nobel, R. (1999) Knowledge Transfer in International Acquisitions. Journal of International Business Studies, 30, 439-462.

https://doi.org/10.1057/palgrave.jibs.8490078

[13] Takemoto, K., Oosawa, C. and Akutsu, T. (2007) Structure of N-Clique Networks Embedded in a Complex Network. Physica A: Statistical Mechanics and Its Applications, 380, 665-672. https://doi.org/10.1016/j.physa.2007.02.042

[14] Chapple, W., Lockett, A., Siegel, D. and Wright, M. (2005) Assessing the Relative Performance of UK University Technology Transfer Offices: Parametric and Non-Parametric Evidence. Research Policy, 34, 369-384. https://doi.org/10.1016/j.respol.2005.01.007

[15] Thursby, J.G. and Kemp, S. (2002) Growth and Productive Efficiency of University Intellectual Property Licensing. Research Policy, 31, 109-124. https://doi.org/10.1016/S0048-7333(00)00160-8

[16] Heher, A.D. (2006) Return on Investment in Innovation: Implications for Institutions and National Agencies. The Journal of Technology Transfer, 31, 403-414. https://doi.org/10.1007/s10961-006-0002-Z

[17] Fan, B.N. and Yu (2015) Study on Regional Differences and Influencing Factors of University Technology Transfer Efficiency. Studies in Science of Science, 33, 18051812.

[18] Cohen, W.M. and Levinthal, D.A. (1990) Absorptive Capacity: A New Perspective on Learning and Innovation. Administrative Science Quarterly, 35, 128-152. https://doi.org/10.2307/2393553 
Submit or recommend next manuscript to SCIRP and we will provide best service for you:

Accepting pre-submission inquiries through Email, Facebook, LinkedIn, Twitter, etc. A wide selection of journals (inclusive of 9 subjects, more than 200 journals)

Providing 24-hour high-quality service

User-friendly online submission system

Fair and swift peer-review system

Efficient typesetting and proofreading procedure

Display of the result of downloads and visits, as well as the number of cited articles Maximum dissemination of your research work

Submit your manuscript at: http://papersubmission.scirp.org/

Or contact jss@scirp.org 